\title{
Challenges during Bone Marrow Transplantation in COVID-19 era
}

\author{
Nahla A M Hamed* \\ Department of Hematology, Faculty of Medicine, Alexandria University, Egypt
}

Submission: December 03, 2020; Published: December 16, 2020

*Corresponding author: Nahla A M Hamed, Department of Hematology, Faculty of Medicine, Alexandria University, Egypt

\begin{abstract}
Which transplant procedure should be delayed during COVID-19 outbreak is a difficult decision due to the variable situation between transplant centers. In general, non-urgent transplants especially those for non-malignant disorders should be deferred as much as possible. Appropriate local advice and support groups are of paramount importance for those who will have treatment delay. Patients might suffer harm if necessary, transplants are delayed due to COVID-19 infection. Patients having undergone SCT require specific guidance and policies. An important issue is deferral of transplant candidates if they become COVID-19 infected.
\end{abstract}

Keywords: Stem cell transplantation; COVID-19 infection; Nasopharyngeal samples; Recommendations

Abbreviations: HCT: Hematopoietic Stem Cell Transplantation; PTCy: Post-transplant Cyclophosphamide; BMI: Body Mass Index; CRS: Cytokine Release Syndrome; BAL: Bronchoalveolar Lavage; PBSCs: Peripheral Blood Stem Cells; EBMT: The European Society for Blood and Marrow Transplantation; GVHD: Graft-Versus-Host-Disease

\section{Introduction}

HCT recipients may be at increased risk for secondary infections and organ damage from COVID-19 [1]. COVID-19 positive patients pre-SCT should be deferred where possible by at least 3 months until they become asymptomatic with viral throat swab negative, 3 repeated tests, 1 week apart (EBMT guidelines). In patients with high-risk disease, HCT should be deferred until the patient is asymptomatic (deferral of 14 days minimum) and has three repeated virus PCR negative at least one week apart [2].

\section{Donor Recommendations}

The donor recommendations produced by VMDA and endorsed by the EBMT are [2]

a) COVID-19 positive donor must be excluded from donation for at least 3 months [2].

b) SARS-CoV-2 RNA can remain detectable by PCR in nasopharyngeal samples for an extended period after full recovery. Nasopharyngeal shedding does not equate to viremia. A donor with detectable nasopharyngeal SARS-CoV-2 RNA have a potential infective risk to staff and other donors at a collection centre [3].

c) Donors in close contact with a COVID-19 positive person shall be excluded from donation for at least 28 days and closely monitored for the presence of COVID-19 [2]. d) Donors who travel to or are in close contact with a person travels to high-risk areas for COVID-19 (as defined by health authorities), shall be excluded from donation for at least 28 days. Donors in the 28 days before donation should practice a good hygiene (according to The WHO recommendations) and avoid crowded places and large group gatherings [2].

e) Earlier collection may be considered if the patient's need for transplant is urgent, the donor is completely well and there are no suitable alternative donor and if careful risk assessment and local quarantine requirements permit [2].

\section{Recipient Recommendations}

a) Stem cell transplanted patients should restrict their exposure to infected individuals by avoiding crowded places, public transport, use good hand hygiene measures including hand washing and use of alcohol containing hand sanitizers and remain in self-isolation at home for 14 days prior to the start of conditioning [2].

b) Stem cell transplant patients should avoid non-necessary travel according to national guidelines [3].

\section{Diagnostic Procedures Guidelines}

a) Patients residing in and patients in close contact with a person residing in an area with high risk of SARS-CoV-2 
transmission (as defined by national authorities, ECDC, or WHO) [2] should be tested for the virus. If SARS-CoV-2 test is negative and there is strong suspicion of COVID-19 infection (false negative) such as case of pneumonia or severe illness, repeat SARS-CoV-2 test and test for other respiratory viral pathogens including influenza and RSV preferably by multiplex PCR [3].

b) All patients positive for SARS-CoV-2 in an upper respiratory tract sample should do chest imaging preferably by CT, and evaluation of oxygenation impairment [4].

c) Routine bronchoalveolar lavage (BAL) is not recommended in SARS-CoV-2 positive patient to avoid transmission amongst health care workers unless a co-infection is suspected [4].

d) Test a lower respiratory tract aspirate or BAL sample for SARS-CoV-2 if chest imaging is abnormal and in clinically indicated patients (e.g., those receiving invasive mechanical ventilation). Co-pathogens should be evaluated and treated [2].

e) Screen all patients for respiratory viruses and SARSCoV-2 at least once $72 \mathrm{hrs}$ before starting conditioning regardless of upper respiratory symptoms as there is an asymptomatic period [2].

\section{Transplant Procedures Recommendations}

a) Minimize the use of chemotherapy priming and use GCS-F alone in autologous transplantation [2].

b) Peripheral blood stem cells (PBSCs) \ with cryopreservation should be preferentially used unless the bone marrow is strongly indicated [1]. Cryopreservation of the product before the start of conditioning is strongly recommended to get secured stem cell product. If this is not possible, an alternative donor must be available as a back-up. The quality of thawed product is strongly encouraged to be tested before the start of conditioning [2].

c) Any transplant procedures (PBSC mobilization, BM harvest, and conditioning) should not be performed within at least 14 preferably 21 days from the last contact in case of having been in a high-risk area or having been in close contact with person travelling from a high-risk area for COVID-19. In case of close contact with a COVID-19 positive person, the patient should be closely monitored for the presence of COVID-19, with confirmed PCR negativity [2].

d) SARS-CoV-2 has been detected rarely in blood. No confirmed or suspected cases of transfusion-transmitted COVID-19 have been reported to date in blood products or cellular therapy by FDA. Current American Association of Blood Banks guidelines do not recommend universal screening for SARSCoV-2 in blood products, and current FDA guidelines recommend considering the donor's infection and exposure history in the 28 days before donation [1].

\section{Peri and Post-transplant Guidelines}

a) Minimize the number of all family members visit and educate them on hand hygiene [2].

b) Patients should be managed in strict protective isolation; risk assess the need for any investigations and procedures outside their isolation room [2].

c) SARS-CoV-2 +ve patients should be isolated in negative pressure cubicles wherever possible, a neutral pressure cubicle may be an alternative [2].

d) After discharge, the time of greatest risk to transplant recipients, reinforce for self-isolation of the transplant recipient and minimize of clinic visits [2].

e) The UK government guidance on shielding and protecting people have to be followed until the risks associated with the COVID-19 pandemic have passed in:

i. All autologous HSCT patients within the last year

ii. Allogeneic HSCT within the last 2 years, or on continuous immunosuppressive therapy, having chronic graft versus host disease (GvHD) or having evidence of ongoing immunodeficiency [5]

\section{Prophylaxis and treatment of COVID-19 in transplant patients}

a) Pre, peri or post-transplant patient with respiratory symptoms should be isolated and screened for respiratory viral pathogens including SARS-CoV-2 [2].

b) No therapy is recommended in COVID-19 +ve patients who present with no or only upper respiratory symptoms pre-SCT [3].

c) Installing therapy and participating in a clinical trial in patients with lower respiratory tract symptoms pre-SCT, should be investigated [3].

d) If COVID-19 infection is diagnosed on the day of transplantation (day 0), then HCT should proceed as intended, with no delays in the PBSC or bone marrow infusion [1].

e) If COVID-19 infection is diagnosed after the stem cell infusion, then it should be treated symptomatically and/or on a clinical trial [1], taking the possibility of manageable drug interactions into account [4].

f) Convalescent plasma infusions should be avoided on the day of transplantation, if indicated for COVID-19 infection on a clinical trial, to minimize the risk of allergic reactions [1]

g) SARS-CoV-2 positive patients should not be treated in rooms with laminar air flow or other rooms (HEPA) with positive pressure unless the ventilation can be turned off [6]. 


\section{Cancer Therapy \& Oncology International Journal}

h) Autologous HCT recipients beyond 6 months post transplantation and allogeneic HCT recipients beyond 1-year post-transplantation without immunosuppression and GVHD may be treated according to general COVID-19 management guidelines and should be cared for in the transplantation center and entered into a clinical trial if available. No poved role for convalescent plasma in treating COVID-19 in the setting of allogeneic HCT [1].

i) Allograft recipients in a recent study who had had non-myeloablative conditioning with post-transplant cyclophosphamide (PTCy) have exhibited mild COVID-19 in spite of comorbid conditions such as body mass index $>35$, or diabetes mellitus. PTCy abrogates cytokine release syndrome (CRS) in haplo-identical stem cell transplantation, mediates direct elimination of allo-reactive T-cell, thymic clonal deletion, and expansion in FoxP3+ CD4+ T-regulatory cells. Moreover, non-myeloablative conditioning causes less tissue damage and possibly fewer risks for severe COVID-19-associated CRS early post allograft and preserves recipients' innate immunity, which is essential for coronaviruses immunity [6].

j) Many of the currently used drugs in the treatment of acute or chronic GVHD such as Bruton's tyrosine kinase inhibitors (eg, ibrutinib), ruxolitinib, tocilizumab, azithromycin, and mesenchymal stromal cells are being studied in clinical trials to evaluate their efficacy (or lack) for treating COVID-19 and/or its complications [7].

\section{Conclusion}

An important question is when and how to manage an HCT recipient who contracts COVID-19 post-transplantation. This should be an individualized decision. At present, it is unclear whether the incidence of the severe syndrome of COVID-19 infection is diminished or enhanced in patients post-HCT relative to the general population or other cancer populations, and what risk factors are predictive of lower respiratory infection and infection severity.

\section{References}

1. Algwaiz G, Aljurf M, Koh M, Horowitz MM, Ljungman P, Weisdorf D, et al. Real-World issues and potential solutions in hematopoietic cell transplantation during the COVID-19 pandemic: Perspectives from the worldwide network for blood and marrow transplantation and center for international blood and marrow transplant research health services and international studies committee Biol Blood Marrow Transplant 2020;1-9.

2. BSBMT\&CT recommendations for the management of adult patients and allogeneic donors CORONAVIRUS disease COVID-19: EBMT recommendations update MARCH 16, 2020 EBMT guideline covid 19 version 32. 22. 03. Available at: www.ebmt.org/sites/ default/files/2020-03/EBMT\%20COVID-19\%20guidelines\%20 v.2\%20\%282020-03-10\%29.pdf ASTCT guidance: https:// higherlogicdownload.s3.amazonaws.com/ASBMT/a1e2ac9a-36d24e23-945c-45118b667268/UploadedImages/COVID-19_Interim_ Patient_Guidelines_3_9_20_V2.pdf .

3. Ljungman P, Styczynski J, Mikulska M, de la Camara R. CORONAVIRUS Disease COVID-19: EBMT recommendations version 8 - MAY 18, 2020.

4. Ljungman P, Mikulska M, de la Camara R, Basak GW, Chabannon C, Corbacioglu S, Duarte R, Dolstra H, Lankester AC, Mohty M, Montoto S, Murray J, de Latour RP, Snowden JA, Yakoub-Agha I, Kröger BVN, Styczynski J, the European Society for Blood and Marrow Transplantation. The challenge of COVID-19 and hematopoietic cell transplantation; EBMT recommendations for management of hematopoietic cell transplant recipients, their donors, and patients undergoing CAR T-cell therapy. Bone Marrow Transplantation 2020;55:2071-2076.

5. COVID-19 rapid guideline: haematopoietic stem cell transplantation NICE guideline Published: 1 April 2020. Available at www.nice.org.uk/ guidance/ng164.

6. Kanellopoulos A, Ahmed MZ, Kishore B, Lovell R, Horgan C, Paneesha SO, et al. COVID-19 in bone marrow transplant recipients: reflecting on a single centre experience Br J Haematol 2020;190:e57-e94.

7. Russell B, Moss C, George G, Santaolalla A, Cope A, Papa S, et al. Associations between immune-suppressive and stimulating drugs and novel COVID-19-a systematic review of current evidence. ecancer

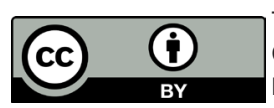

This work is licensed under Creative Commons Attribution 4.0 License DOI:10.19080/CTOIJ.2020.17.555969
Your next submission with Juniper Publishers will reach you the below assets

- Quality Editorial service

- Swift Peer Review

- Reprints availability

- E-prints Service

- Manuscript Podcast for convenient understanding

- Global attainment for your research

- Manuscript accessibility in different formats ( Pdf, E-pub, Full Text, Audio)

- Unceasing customer service

Track the below URL for one-step submission https://juniperpublishers.com/online-submission.php 